Boise State University

ScholarWorks

Counselor Education Faculty Publications and

Presentations

Department of Counselor Education

1-1-2009

\title{
Evaluation of Two Web-Based Alcohol Interventions for Mandated College Students
}

Diana M. Doumas

Boise State University

Lisa L. McKinley

Boise State University

Phares Book

Boise State University

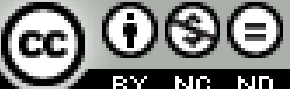

This is an author-produced, peer-reviewed version of this article. (c) 2009, Elsevier. Licensed under the Creative Commons Attribution-NonCommercial-NoDerivs 3.0 License: https://creativecommons.org/licenses/by-nc-nd/3.0/. The final, definitive version of this document can be found online at the Journal of Substance Abuse Treatment, doi: 10.1016/j.jsat.2008.05.009 


\title{
Evaluation of Two Web-Based Alcohol Interventions for Mandated College Students
}

\author{
Diana M. Doumas \\ Department of Counselor Education, Institute for the Study of Addiction \\ Boise State University, Boise, ID 83725 USA \\ Lisa L. McKinley \\ Department of Psychology \\ Boise State University, Boise, ID 83725 USA \\ Phares Book \\ Counseling Services \\ Boise State University, Boise, ID 83725 USA
}

\begin{abstract}
This study evaluated the efficacy of two web-based interventions aimed at reducing heavy drinking in mandated college students. Mandated students were randomly assigned to one of two conditions: web-based personalized normative feedback (WPNF) or web-based education (WE). As predicted, results indicated mandated students in the WPNF condition reported significantly greater reductions in weekly drinking quantity, peak alcohol consumption, and frequency of drinking to intoxication than students in the WE condition at a 30-day follow-up. Although not statistically significant, there was a similar trend for changes in alcohol-related problems. Mandated students in the WPNF group also reported significantly greater reductions in estimates of peer drinking from baseline to the followup assessment than students in the WE group. Additionally, changes in estimates of peer drinking mediated the effect of the intervention on changes in drinking. Findings provide support for providing web-based personalized normative feedback as an intervention program for mandated college students.
\end{abstract}

Key Words: alcohol; mandated students; normative feedback; online; web-based

\section{Introduction}

Heavy drinking represents a significant problem on college campuses in the United States, with over $30 \%$ of college students meeting criteria for a diagnosis of alcohol abuse (Knight, et al., 2002). Similarly, national survey data from approximately 14,000 students indicate that $44 \%$ of students report binge drinking, defined as 5 or more drinks in a row for males and 4 or more for females, at least once in the past 2 weeks, with $23 \%$ of those reporting binge drinking three or more times in the past 2 weeks (Wechsler, Lee, Kuo, \& Lee, 2000). Further, heavy drinking is associated with multiple social and interpersonal problems such as arguing with friends, engaging in unplanned sexual activity, drinking and driving, getting into trouble with the law, academic difficulties, unintended injuries, assault, and death (Abbey, 2002; Cooper, 2002; Hingson, Heeren, Zakocs, Kopstein, \& Wechsler, 2002; Hingson, Heeren,Winter, \& Wechsler, 2005; Perkins, 2002; Vik, Carrello, Tate, \& Field, 2000; Wechsler et al., 2000).

Correspondence concerning this article should be addressed to Diana M. Doumas, Department of Counselor Education, Boise State University, 1910 University Drive, Boise, ID 83725, USA. Phone: (208) 426-2646. Fax: (208) 426-2046. E-mail: dianadoumas@boisestate.edu.
Over the past decade, alcohol prevention programs have been implemented on college campuses in an effort to reduce heavy drinking among college students. Binge drinking, however, remains a significant problem on college campuses across the nation (Weschler et al., 2002). In addition, mandated students have been identified as a high-risk group for heavy drinking relative to the general college population (Larimer \& Cronce, 2002; 2007). According to a recent review conducted by Barnett and Read (2005), studies examining drinking patterns on college campuses indicate that mandated students drink more heavily and report more alcohol-related problems than other college students and that there has been an increase in the number of alcohol-related arrests, the number of students receiving alcohol citations, and the proportion of students mandated to participate in a post-citation intervention on college campuses. These statistics point to the importance of developing effective, low-cost, and easily disseminated interventions for college students receiving alcohol-related sanctions.

Several social explanations for the high rates of drinking found in the college student population have been proposed. Of these, peer influence has gained attention in the literature as an important variable that may be related to the elevated levels of drinking seen 
on college campuses. According to social norming theory (Perkins, 2002), college students overestimate the amount of alcohol their peers consume and this overestimation leads to participation in heavy drinking as students attempt to match their drinking levels to their perceptions of peer alcohol use. Research supporting social norming theory confirms that college students typically overestimate the amount of alcohol use among their peers (Baer, Stacy, \& Larimer, 1991; Borsari \& Carey, 2001). Additionally, research indicates interventions that provide normative feedback about peer drinking are associated with reductions in alcohol consumption and that changes in estimates of peer drinking mediate the intervention effects on the reductions in drinking (Neighbors, Larimer, \& Lewis, 2004; Walters, Vader, \& Harris, 2007). These finding suggest that providing accurate feedback regarding peer drinking results in both a downward adjustment in estimates of peer drinking and a reduction of heavy drinking in college students.

Recent reviews of the literature support the efficacy of brief interventions using motivational interviewing (see Miller \& Rollnick, 2002) and personalized normative feedback for reducing heavy drinking in college students (Burke, Arkowitz, \& Menchola, 2003; Carey, Scott-Sheldon, Carey, \& DeMartini, 2007; Larimer \& Cronce, 2007; Moyer, Finney, Swearingen, \& Vergun, 2002). Personalized feedback typically includes information about drinking and drinking risk-status relative to peer drinking normative data (Larimer et al., 2001; Marlatt et al., 1998) and is generally delivered as a central component of brief motivational interventions. Over the past few years, innovative approaches to implementing brief motivational interventions have also been developed. Recent reviews of the literature indicate feedback, whether delivered in-person, by mail, or electronically, can be effective in reducing heavy drinking among college students (Larimer \& Cronce, 2007; Walters \& Neighbors, 2005). There are, however, many advantages to using web-based programs with college students (Walters, Miller, \& Chiauzzi, 2005). Research indicates young drinkers tend to respond better to electronic feedback than to in person feedback (Larimer \& Cronce, 2002; Kypri, Saunders, \& Gallagher, 2003; Saunders, Kypri, Walters, Laforge, \& Larimer, 2004). While students may be skeptical about discussing their drinking with a health practitioner, they are interested in how their drinking compares with the drinking of their peers. Web-based feedback interventions appeal to this curiosity while reducing apprehension associated with talking to a professional. Further, in contrast to the typical one week interval occurring between assessment and delivery of either in-person or mailed feedback, web-based programs produce immediate feedback for participants.

Although mandated students have been identified as a high-risk population for heavy drinking relative to the general college student population (Barnett \& Read, 2005; Larimer \& Cronce, 2007) and research indicates brief interventions providing personalized feedback are effective in reducing high-risk drinking in college students (Burke et al., 2003; Carey et al., 2007; Larimer \& Cronce, 2007; Moyer et al., 2002), there have been few systematic studies of brief motivational interventions for mandated students. Additionally, the majority of studies examining the efficacy of programs for mandated students have used a single-group design (see Barnett \& Read, 2005), limiting the ability to determine whether changes in drinking and alcohol-related problems are related to the intervention or to the alcohol sanction itself. To date, only three studies examining brief motivational interventions for mandated students using a randomized controlled design with a comparison group have been published (Barnett et al. 2004; Borsari \& Carey, 2005; White et al., 2006); two of these also published data from long-term follow-up assessments (Barnett, Murphy, Colby, \& Monti, 2007; White, Mun, Pugh, \& Morgan, 2007). Overall, these studies suggest brief interventions providing personalized normative feedback are effective in reducing drinking and alcohol-related problems in mandated students.

In a study of high-risk mandated students, Borsari and Carey (2005) compared the efficacy of two brief in-person interventions for reducing drinking and alcohol-related problems among mandated students screened and classified as heavy drinkers (approximately $60 \%$ of the mandated students). Selected students were randomly assigned to complete either a brief motivational intervention ( $\mathrm{n}$ $=34$ ) or a standard alcohol education session ( $\mathrm{n}=$ 30). Results at a 6-month follow-up indicated both groups decreased their binge drinking, and the motivational intervention group showed a significantly higher reduction in alcohol-related problems than the education group.

In a larger study with a longer follow-up period, Barnett et al. (2004; 2007) examined the efficacy of two interventions for mandated students referred following a disciplinary hearing for an alcohol infraction or medical evaluation for intoxication. The study compared two conditions: a one-session brief motivational interview (BMI; $n=112$ ) and a 45 minute session reviewing an educational $\mathrm{CD}$ (Alcohol 101; $\mathrm{n}=113$ ). At the 3-month follow-up, although both groups decreased their drinking, there were no changes in alcohol-related problems. Results 
of a 12-month follow-up indicated mandated students in the Alcohol 101 group increased the number of drinks per drinking occasion relative to the BMI group, whereas the students in the BMI group reported an increase in drinking frequency relative to those in the Alcohol 101 group. Consistent with the 3-month follow-up, there were no changes in alcoholrelated problems.

In another large-scale study with a long-term follow-up, White et al. (2006; 2007) examined the efficacy of a two-session brief personalized feedback program, comparing BASICS (Dimeff, Baer, Kivlahan, \& Marlatt, 1999) delivered either in an inperson motivational feedback session $(n=118)$ or in a written feedback condition $(n=104)$. At a 3 -month follow-up, both groups decreased the total number of drinks per week, the frequency of binge drinking, and alcohol-related problems. However, no significant differences were identified between the in-person feedback and written feedback conditions. Results of a 15-month follow-up assessment, however, indicated that mandated students reduced their drinking and alcohol-related problems from the baseline assessment and this reduction was primarily accounted for by the students in the in-person motivational feedback session (White et al., 2007). The authors suggest that although their initial findings demonstrated no differences between inperson and written feedback, there may be a "sleeper effect" that favors the in-person feedback over the long-term.

Although only a few controlled studies have examined brief motivational interventions with mandated students, findings generally support the use of these interventions with this group of college students. To date, however, no studies have examined the efficacy of a web-based personalized normative feedback program with mandated students. Although Barnett et al. (2004; 2007) used a computerized program, the program was primarily educational and it is not clear from the study whether or not an optional personalized feedback component available in the program was viewed by the students. Similarly, although White et al. (2006; 2007) examined differences between in-person and written feedback, for both, the feedback was given during a second session occurring approximately one week after the assessment session. Web-based feedback differs from written feedback in that web-based feedback is delivered immediately to students once they complete the alcohol assessment. Additionally, although research indicates that changes in estimates of peer drinking mediate the impact of the intervention on changes in drinking in college students (Neighbors et al., 2004; Walters et al., 2007), to date, changes in peer drinking estimates have not been examined as a mediator in the relationship between intervention effects and drinking reductions in mandated students.

The aim of the current study is to extend the literature by examining the efficacy of a web-based personalized normative feedback program in reducing heavy drinking and alcohol-related problems in mandated college students and by examining changes in peer drinking estimates as a mediator of the effects of the intervention on changes in drinking. To achieve these aims, we randomly assigned mandated college students to one of two conditions: web-based personalized normative feedback (WPNF) or web-based education (WE). The following hypotheses were examined: 1) mandated students receiving web-based personalized normative feedback will report greater reductions in drinking and alcohol-related problems compared to those in the WE condition, 2) mandated students will estimate typical student drinking to be higher than their own drinking, 3) mandated students in the WPNF group will reduce estimates of peer drinking norms more than those in the WE condition, and 4) changes in peer drinking estimates will mediate the effect of the intervention on changes in drinking.

\section{Method}

\subsection{Participants}

The participants in this study were students who were referred to University Counseling Services for violating the University policy for alcohol and other drugs from Spring 2006 to Fall 2007. Referrals were made by staff in Residence Life (72\%), the Student Conduct Office (11\%), and the Athletic Department $(17 \%)$. Mandated students were given an opportunity to participate in the study and were not offered compensation for their participation. All participants were treated according to established APA ethical standards, and the University Institutional Review Board approved all research procedures.

Of 106 mandated students referred to Counseling Services, 83 were referred for an alcohol-related citation. Of these, five declined to participate in the study, one was ineligible due to age (the student was a minor), and one was eliminated due to a computer error in delivering personalized feedback. Of the remaining 76 students, $72.4 \%$ were male and $27.6 \%$ were female. Ages of the students ranged from 18-24 $(\mathrm{M}=19.24, \mathrm{SD}=1.33)$. The majority of students were Caucasian (85.5\%), with $5.3 \%$ African American, 2.6\% Asian American, 2.6\% Native American, $2.6 \%$ Hispanic, and $1.3 \%$ other. Students were primarily freshmen $(48.7 \%)$ and sophomores (38.2\%), with $9.2 \%$ juniors and $3.9 \%$ seniors. Participants were randomly assigned to either the WPNF or the WE condition using a computer- 
generated random numbers table. Forty-six (59.2\%) students were assigned to the WPNF condition and $31(40.8 \%)$ were assigned to the WE condition. Chisquare analyses and t-tests confirmed there were no significant differences in any of the demographic or baseline drinking variables between the groups.

\subsection{Measures}

\subsubsection{Alcohol consumption}

Recommendations by the National Institute on Alcohol Abuse and Alcoholism (NIAAA) Task Force include assessing patterns of alcohol consumption in addition to the average number of drinks consumed and including at least three measures of consumption covering quantity, frequency, and heavy consumption (NIAAA, 2003). We included three measures of alcohol consumption: drinking quantity, peak consumption, and frequency of drinking to intoxication. Typical quantity of weekly drinking was assessed using a modified version of the Daily Drinking Questionnaire (DDQ, Collins, Parks, \& Marlatt, 1985). This item asks participants to indicate how much they typically drink, "Given that it is a typical week, please write the number of drinks you probably would have each day." A response scale is provided for each day of the week (e.g., Monday__, Tuesday___, etc.). Weekly drinking was calculated by combining the reports for the seven days of the week. Peak alcohol consumption was assessed by an item asking the participants to indicate the number of drinks consumed on the occasion on which they drank the most in the previous month. Frequency of drinking to intoxication was assessed by the question "During the past 30 days (about 1 month), how many times have you gotten drunk, or very high from alcohol?" This item was rated on a 6 -point scale with the anchors 0 , 1 to 2,3 to 4,5 to 6,7 to 8 , or $>9$ times. Due to nonnormality, frequency of drinking to intoxication was dichotomized into never intoxicated versus intoxicated at least once in the last month.

\subsubsection{Alcohol-related problems}

Alcohol-related problems were assessed using the Rutgers Alcohol Problem Index (RAPI; White \& Labouvie, 1989). The RAPI is a 23-item selfadministered screening tool used to measure adolescent problem drinking. Participants were asked the number of times in the past 30 days they experienced each of 23 negative consequences as a result of drinking. Responses were measured on a 5point scale ranging from never to more than 10 times. A total consequence score was created by summing the 23 items. The RAPI assesses both traditional physical consequences (e.g., tolerance, withdrawal symptoms, physical dependency) and consequences presumed to occur at higher rates in a college student population (e.g., missing school, not doing homework, going to school drunk). The RAPI has good internal consistency (Neal \& Carey, 2004) and test-retest reliability (Miller, et al., 2002).

\subsubsection{Perceived peer drinking norms}

Weekly drinking estimates for typical college students were assessed using a modified version of the Daily Drinking Questionnaire (DDQ, Collins et al., 1985). Participants were asked to estimate the number of drinks they believed a typical college student would have in a typical week for each day of the week, "Given that it is a typical week, please write the number of drinks you believe a typical college student probably would have each day." A response scale is provided for each day of the week (e.g., Monday__, Tuesday__, etc.). Weekly estimates of typical college student drinking were each calculated by combining the reported estimates for the seven days of the week.

\subsection{Intervention}

Mandated students were randomly assigned to one of two interventions: 1) a web-based personalized normative feedback intervention and 2) a web-based education intervention. The two conditions are described below.

2.3.1. Web-based personalized normative feedback intervention (WPNF)

Participants in the WPNF condition completed a 15-minute web-based program designed to reduce high-risk drinking by providing personalized feedback and normative data regarding drinking and the risks associated with drinking. The program is free to the public and is available at http://notes.camh.net/efeed.nsf/newform (for a full description of the program, see Cunningham, Humphreys, \& Koski-Jannes, 2000). An updated version of this program is now available at www.CheckYourDrinking.net. The online assessment collects basic demographic information and information on alcohol consumption, drinking behavior, and alcohol-related consequences. Individualized graphed feedback is provided immediately in the following domains: a pie chart depicting individual levels of drinking in relation to U.S. peer norms, a summary of the number of days the participant consumed alcohol and number of drinks consumed in the past year, approximate financial cost of drinking in the past year, calories associated with drinking, how quickly the body processes alcohol, risk-status for negative consequences associated with drinking, and risk-status for problematic drinking based on the participant's AUDIT score.

Research indicates this web-based program is widely accessed, with approximately 500 hits per month (Cunningham et al., 2000). In addition, of those responding to a survey about the website, $56 \%$ 
indicated they found the feedback very or extremely useful and $53 \%$ of problem drinkers said they were surprised by how much more they drank than other people (Cunningham et al., 2000). Further, research examining the efficacy of this website indicates those participating in the website intervention reported a significant decrease in their severity of alcoholrelated problems, and the benefits were even greater with the addition of a self-help book (Cunningham, Humphreys, Koski-Jannes, \& Cordingley, 2005). Additionally, high-risk college-aged students in the workplace (Doumas \& Hannah, 2008) and high-risk collegiate athletes (Doumas \& Haustveit, in press) participating in this web-based program decreased their drinking more than high-risk participants in comparison conditions.

\subsubsection{Web-based education condition (WE)}

Participants in the WE group completed the Judicial Educator located at www.reslife.net. The Judicial Educator is a commercially-available program that was developed to provide an easily administered educational program for students receiving disciplinary sanctions (Scanlon, n.d.). For this study we used the Alcohol Module, an automated computerized program that presents general information about alcohol, including rates of alcohol use on college campuses, physical effects of alcohol, short-term and long-term negative alcohol-related consequences, sensible alcohol consumption, and strategies to help friends struggling with problematic alcohol use. Following the computerized presentation, participants are directed to take a 10 -item quiz over the material to test their learning. The Judicial Educator takes approximately 45 minutes to complete.

\subsection{Procedure}

All procedures were completed at the University Counseling Services with an advanced Masters in Counseling graduate student. Mandated students received instructions for scheduling an appointment from the source of referral and were scheduled within two weeks of the policy violation. During the first appointment, participants were informed of the nature of the study, risks and benefits of participation, and the voluntary nature of participation. All questionnaires at baseline and follow-up assessments were completed in pen-and-paper format. During the baseline data collection, students were assigned a personal code. This code was used to identify preand post-intervention responses from each student, as well as to calculate response rates from baseline to follow-up assessments. Participants completed baseline questionnaires and either the WPNF or WE program. Once the intervention was completed, students set up an appointment for a 30-day followup session. The average appointment length ranged from 30-50 minutes $(\mathrm{M}=37.30, \mathrm{SD}=6.42)$ for the WPNF condition and 35-90 minutes $(\mathrm{M}=49.19$, SD $=11.98$ ) for the WE condition. During the 30-minute follow-up session, participants completed follow-up questionnaires and then participated in a brief session in which the MA in Counseling student reviewed the student's current drinking and any concerns related to drinking. Students were provided a referral to Counseling Services either for ongoing alcoholrelated problems or for future issues or concerns.

\section{Results}

\subsection{Attrition}

Of the 76 participants, 67 (88.2\%) completed the 30-day follow-up assessment. There was no difference in the rate of attrition across the two intervention groups, $\square 2=1.46, \mathrm{p}=.23$. In addition, a series of chi-square and t-tests revealed no differences in demographic variables or in any of the drinking variables between the participants who completed the program and those who did not.

\subsection{Statistical analyses}

We first examined the data for extreme cases that might impact the results of the analyses. Extreme cases were defined as those that were more than three standard deviations from the mean on any of the drinking measures at baseline. This resulted in eliminating three study participants. We also examined the data for missing items. We defined incomplete data as leaving more than $50 \%$ of items blank. This procedure resulted in the exclusion of an additional three participants. A total of six participants were excluded in the preliminary examination of the data, resulting in a final sample size of 61 mandated student completing both baseline and follow-up assessments. Additionally, because there was a significant difference in length of appointment between the two conditions, $\mathrm{t}(60)=-$ $5.65, \mathrm{p}<.001$, length of appointment was controlled for in all analyses comparing outcomes for the two groups.

3.3. Alcohol consumption and alcohol-related problems

3.3.1. Did the intervention change alcohol consumption?

To examine whether students in the WPNF group would report significantly greater reductions in drinking relative to those in the WE group at the 30day follow-up, a repeated measures multivariate analyses of variance (MANOVA) was conducted. The two independent variables in the analysis were Time (baseline; 30-day follow-up) and Group (WPNF; WE). The three drinking measures included as dependent variables were quantity of weekly 
drinking, peak alcohol consumption, and frequency of drinking to intoxication.

Means for alcohol consumption measures at baseline and the 30-day follow-up assessment are shown in Table 1. Results of the repeated-measures MANOVA indicated a significant interaction effect for Time x Group, Wilks' Lambda $=.86, \mathrm{~F}(3,57)=$ 2.94, $\mathrm{p}=.04$, eta $2=.14$. Follow-up univariate analyses of variance revealed a significant Time $\mathrm{x}$ Group interaction for weekly drinking, $F(1,59)=$ $4.16, \mathrm{p}<.05$, eta $2=.07$, peak alcohol consumption, $\mathrm{F}(1,59)=5.04, \mathrm{p}<.03$, eta2 $=.08$, and frequency of drinking to intoxication, $\mathrm{F}(1,59)=4.26, \mathrm{p}<.05$, eta2 $=.07$. As predicted, for weekly drinking, peak alcohol consumption, and frequency of drinking to intoxication, mandated students in the WPNF intervention group reduced their drinking significantly more than those in the WE condition (see Figure 1).

Examination of the means in Table 1 indicates that mandated students in the WPNF group reduced their weekly drinking quantity by an average of 3.27 drinks per week at the 30-day follow-up (approximately 40\% reduction in quantity) compared to a reduction of 1.27 drinks in the WE group (an $18 \%$ reduction). Similarly, mandated students in the WPNF group reduced their peak drinking quantity by 1.82 drinks on average (approximately $21 \%$ reduction in the quantity) compared to a reduction of 0.33 drinks in the WE group (a 5\% reduction). Finally, mandated students in the WPNF group reduced their frequency of drinking to intoxication by $19 \%$ compared to a reduction of $10 \%$ in the WE group.

3.3.2. Did the intervention change alcoholrelated problems?

To examine whether students in the WPNF group would report significantly greater reductions in drinking relative to those in the WE group at the 30day follow-up, we conducted a repeated measures analyses of variance (ANOVA) using the same two independent variables as the previous analyses. Means for alcohol-related problems at baseline and 30-day follow-up assessment are shown in Table 1. Although results were not significant for the Time $\mathrm{x}$ Group interaction, Wilks' Lambda $=.98, \mathrm{~F}(1,59)=$ $1.51, \mathrm{p}=.23$, eta $2=.03$, examination of the means in Table 1 indicates that mandated students in the WPNF group reported a $53 \%$ reduction in alcoholrelated problems compared to a $42 \%$ reduction in the WE group.

\subsection{Perception of peer drinking norms}

3.4.1. Do mandated students overestimate peer drinking?

Baseline reports for self and typical college student drinking indicated mandated students reported drinking fewer drinks per week $(\mathrm{M}=7.72$, $\mathrm{SD}=6.09)$ than they estimated a typical college student drinks $(\mathrm{M}=14.04, \mathrm{SD}=8.09)$. Results of a paired t-tests indicated a significant differences between self-report and report of a typical college student, $\mathrm{t}(60)=-6.98, \mathrm{p}<.001$. As predicted, results indicate that the mandated students in this sample overestimated levels of college student weekly drinking relative to their own drinking at the baseline assessment, believing typical students drink twice as much as they drink themselves.

3.4.2. Did the intervention change estimates of peer drinking?

To examine differences in estimates of peer drinking from baseline to the 30-day follow-up, we conducted a repeated measures analyses of variance (ANOVA). The two independent variables in the analysis were Time (baseline; 30-day follow-up) and Group (WPNF; WE). The dependent variable was the estimated weekly drinking quantity for a typical college student. Means and standard deviations for estimates of peer weekly drinking at baseline and 30day follow-up assessment by study condition are shown in Table 1. Results of the repeated-measures ANOVA indicated a significant interaction effect for Time x Group, Wilks' Lambda $=.92, \mathrm{~F}(1,58)=5.33$, $\mathrm{p}=.03$, eta $2=.08$, indicating a significant reduction in peer drinking estimates for mandated students in the WPNF group compared to those in the WE group.

3.5. Did the change in estimates of peer drinking mediate the effect of the intervention on changes in drinking?

We next conducted a series of hierarchical regression analyses to examine whether the effect of the intervention on drinking could be explained by the change in estimates of peer drinking. Following Baron \& Kenny (1986), separate regression analyses were conducted to determine whether the intervention was significantly associated with changes in estimates of peer drinking, whether changes in estimates of peer drinking predicted changes in drinking, and whether the effect of the intervention on drinking was accounted for by changes in peer drinking estimates. Change scores from baseline to the 30-day follow-up were calculated for both estimates of peer drinking and weekly drinking. Again, because there was a significant difference in length of appointment between the two intervention conditions, length of appointment was controlled for in the following analyses.

As hypothesized, results of a series of regression analyses indicated changes in estimates of peer drinking mediated the relationship between the effect of the intervention and changes in drinking. Specifically, the intervention predicted changes in estimates of peer drinking $(\beta=.34, p<.05)$ and estimates of peer drinking predicted changes in drinking $(\beta=.50, \mathrm{p}<.001)$. In the final regression, 
the intervention predicted changes in drinking and the effect of the intervention on changes in drinking was no longer significant after controlling for the effect of changes in estimates of peer drinking (see Table 2).

\section{Discussion}

The primary aim of this study was to evaluate the efficacy of a web-based personalized normative feedback program relative to a web-based education program in reducing heavy drinking and alcoholrelated problems among mandated college students. Although research indicates brief interventions are effective in reducing heavy drinking and alcoholrelated consequences in mandated students (Barnett et al., 2004; 2007; Borsari \& Carey, 2005; White et al., 2006; 2007) and web-based personalized normative feedback is effective for reducing highrisk drinking in college students (see Larimer \& Cronce, 2007; Walters et al., 2005; Walters \& Neighbors, 2005), this is the first study to examine the efficacy of a web-based program providing immediate personalized normative feedback for mandated students. Additionally, this is the first study to examine the change in estimates of peer drinking as a mediator in the relationship between the intervention effects and changes in drinking for mandated students. Thus, this study adds to the growing body of literature supporting the use of webbased personalized normative feedback programs and identifies an intervention strategy that effectively reduced drinking in this sample of mandated college students relative to the comparison condition.

Results of this study confirmed the hypothesis that the reductions in drinking in the WPNF condition would be significantly greater than reductions in the WE condition. Although both groups reported a reduction in drinking, mandated students who received web-based personalized normative feedback reported greater reductions in weekly drinking, peak alcohol consumption, and frequency of drinking to intoxication than those in the WE condition. Mandated students in the WPNF group reported a $40 \%$ reduction in weekly drinking quantity, a $20 \%$ reduction in peak drinking levels, and an $18 \%$ reduction in frequency of drinking to intoxication compared to $18 \%, 5 \%$, and $10 \%$ reductions in these drinking variables, respectively, in the WE condition. These findings are consistent with research indicating that web-based personalized feedback programs are effective in reducing heavy drinking in college students (see Larimer \& Cronce, 2007) and brief interventions providing in-person normative feedback are effective for mandated students (Barnett et al., 2004; Borsari and Carey, 2005; White et al., 2007).
Contrary to our hypotheses, we did not find a significant reduction in alcohol-related problems for either intervention condition. Mandated students in the WPNF group did, however, report larger reductions in alcohol-related problems than students in the WE group, although this difference was not statistically significant. Prior research examining changes in alcohol-related problems is mixed, with some studies indicating mandated students receiving personalized feedback report fewer alcohol-related problems than those receiving education (Borsari \& Carey, 2005), whereas other studies have not found significant differences in changes in alcohol-related consequences between these two types of interventions (Barnett et al., 2004; 2007). Inconsistencies across studies are unlikely due to measurement differences, sample size, or statistical power, as there is no systematic pattern in the use of a particular instrument with significant findings and the study with the largest sample did not find significant differences between the two groups (Barnett et al., 2004 ; 2007). It is possible that selection issues contribute to the inconsistencies, as group differences were found in the mandated student sample that was screened for high-risk drinking. This suggests that the impact of personalized feedback on alcohol-related problems may be more pronounced relative to education on mandated students at the highest levels of consumption and risk.

Results of this study also indicated mandated students estimated that typical college students drink more than their own self-reported drinking. The direction and magnitude of the means were consistent with research indicating college students generally believe their peers drink more than they do (Baer et al., 1991; Borsari \& Carey, 2001). This is particularly interesting in light of the fact that these students were sanctioned for receiving a campus alcohol policy violation. Despite their involvement in alcohol consumption resulting in a sanction, these students still believe that a typical student drinks twice as much as they drink themselves. Findings also supported the hypothesis that mandated students receiving personalized normative feedback would adjust their beliefs about peer drinking downward. Mandated students receiving accurate information about typical college student drinking reported a reduction in the perception of typical student drinking at the 30-day follow-up relative to the mandated students who did not receive normative data.

Results also indicated changes in estimates of typical college student drinking from baseline to the 30-day follow-up mediated the effect of the intervention on changes in drinking quantity. That is, the effects of the intervention were accounted for by the changes in estimates of peer drinking. Although 
estimates of peer drinking and one's own drinking were reported at the same time, results of the mediation analysis suggest that the WPNF intervention led to a reduction in estimates of peer drinking which, in turn, led to a reduction in drinking quantity. These findings are consistent with previous research on web-based feedback programs for college students indicating the effect of the intervention on reductions in drinking are mediated by reductions in estimates of peer drinking (Neighbors et al., 2004; Walters et al., 2007).

Although this study adds to the literature by demonstrating the efficacy of a web-based personalized feedback program for decreasing drinking among mandated college students, there are several limitations. First, the small sample size and attrition rate in this study limit the generalizability of the results. Although $93 \%$ of students cited with an alcohol policy violation participated in this study, only $88.2 \%$ of those completed the 30 -day follow-up assessment. Although attrition and selection are important issues to consider in interpreting the findings, a high percentage of mandated students did participate in this study, the completion rate was high relative to similar studies, and there were no differences in any demographic or drinking variables between those who completed the study and those who did not. Further, attrition rates were similar across study conditions, suggesting attrition was not related to the particular study condition. Future research with larger sample sizes, however, is recommended to replicate the findings in this study. Second, information in this study was obtained through self-report. Although self-report potentially leads to biased or distorted reporting, self-reported alcohol use is common practice in studies evaluating computerized interventions (Bersamin, Paschall, Fearnow-Kenney, \& Wyrick, 2007; Chiauzzi, Green, Lord, Thum, \& Goldstein, 2005; Doumas \& Hannah, 2008; Doumas \& Haustveit, in press; Kypri et al., 2004; Neighbors et al., 2004; Walters et al., 2007). Additionally, research indicates that the reliability of self-report is adequate (Marlatt et al., 1998). Finally, the duration of the 30-day follow-up was quite short. Although effects of web-based personalized feedback have been shown to last for up to 6 months in college students (Neighbors et al., 2004), future research should include examining the efficacy of web-based programs implemented for mandated college across at least 6 months. Additionally, White et al. (2006; 2007) found differences in drinking reductions reported by mandated students receiving in-person or written feedback at 15 months that were not demonstrated at 3 months, suggesting even longerterm follow-up assessments may be necessary.
Nonetheless, results of this study have important implications for developing early intervention programs for mandated college students. Despite intervention efforts, mandated students remain a high-risk population for drinking and drinking-related problems on college campuses. Additionally, although personalized normative feedback programs are more effective than educational programs in decreasing alcohol use in the college student population (Larimer \& Cronce, 2002; 2007), group lecture-based alcohol education is still a common practice used in intervention programming. This common practice may be the result of the limited amount of outcome studies examining individual brief motivational interventions in the literature. Alternatively, cost may be a factor in selecting both group formats and educational formats for early intervention programs. Results of this study suggest providing web-based normative feedback as an early intervention program is a promising strategy for the reduction of high-risk drinking in the mandated student population. Because of the low cost, ease of dissemination, and efficacy associated with webbased personalized feedback, this type of programming is ideal for both large colleges and universities and campuses that do not have many resources for intervention programming. Directions for future research include examining the impact of web-based personalized normative feedback with a larger sample and over a longer follow-up period, as well as comparing the efficacy of web-based feedback to in-person feedback.

\section{Acknowledgements}

The authors wish to thank Tonya Haustveit and Katie Jacobs for their assistance in project management. The authors also wish to thank Lisa Parker, Blaine Eckles, and Melissa Wintrow for their support of this program.

A limited portion of this manuscript was presented at the annual meeting of the Idaho Counseling Association, January 2008.

\section{References}

Abbey, A. (2002). Alcohol-related sexual assault: A common problem among college students. Journal of Studies on Alcohol, Supplement, 14, 118-128.

Baer, J. S., Stacy, A., \& Larimer, M. (1991). Biases in the perception of drinking norms among college students. Journal of Studies on Alcohol, 54, 54-60. 
Barnett, N. P., Murphy, J. G., Colby, S. M., \& Monti, P. M. (2007). Efficacy of counselor vs. computer-delivered intervention with mandated college students. Addictive Behaviors, 32, 2529 2548.

Barnett, N. P., \& Read, J. P. (2005). Mandatory alcohol intervention for alcohol-abusing college students: A systematic review. Journal of Substance Abuse Treatment, 29, 147-158.

Barnett, N. P., Tevyaw, T. O., Fromme, K., Borsari, B., Carey, K. B., Corbin, W. R., et al. (2004). Brief alcohol interventions with mandated or adjudicated college students. Alcoholism, Clinical and Experimental Research, 28, 966975.

Baron, R. M., \& Kenny, D. A. (1986). The moderator-mediator variable distinction in social psychological research: Conceptual, strategic, and statistical considerations. Journal of Personality and Social Psychology, 51, 11731182.

Bersamin, M., Paschall, M. J., Fearnow-Kenney, M., \& Wyrick, D. (2007). Effectiveness of a webbased alcohol-misuse and harm-prevention course among high- and low-risk students. Journal of American College Health, 55, 247254.

Borsari, B., \& Carey, K. B. (2001). Peer influences on college drinking: A review of the research. Journal of Substance Abuse, 13, 391-424.

Borsari, B., \& Carey, K.B. (2005). Two brief alcohol interventions for mandated college students. Psychology of Addictive Behaviors, 19, 296302.

Burke, B., Arkowitz, H., \& Menchola, M. (2003). The efficacy of motivational interviewing: A meta-analysis of controlled clinical trials. Journal of Consulting and Clinical Psychology, 71, 843861.

Carey, K. B., Scott-Sheldon, L. A. J., Carey, M. P., \& DeMartini, K. S. (2007). Individual-level interventions to reduce college student drinking: A meta-analytic review. Addictive Behaviors, 32, 2469-2494.

Chiauzzi, E., Green, T.C., Lord, S., Thum, C., \& Goldstein, M. (2005). My Student Body: A highrisk drinking prevention web site for college students. Journal of American College Health, 53, 263-274.

Collins, R. L., Parks, G. A., \& Marlatt, G. A. (1985). Social determinants of alcohol consumption: The effects of social interaction and model status on the self-administration of alcohol. Journal of Consulting and Clinical Psychology, 53, 189200.
Cooper, M. L. (2002). Alcohol use and risky sexual behavior among college students and youth: Evaluating the evidence. Journal of Studies on Alcohol, Supplement, 14, 101-117.

Cunningham, J. A., Humphreys, K., \& Koski-Jannes, A. (2000). Providing personalized assessment feedback for problem drinking on the internet: A pilot project. Journal of Studies on Alcohol, 63, 794-798.

Cunningham, J. A., Humphreys, K., Koski-Jannes, A., \& Cordingley, J. (2005). Internet and paper self-help materials for problem drinking: is there an additive effect? Addictive Behaviors, 30, 1517-1523.

Dimeff, L. A., Baer, J. S., Kivlahan, D. R., \& Marlatt, G. A. (1999). Brief Alcohol Screening and Intervention for College Students (BASICS): A Harm Reduction Approach. New York: Guilford Press.

Doumas, D. M., \& Hannah, E. (2008). Preventing high-risk drinking in youth in the workplace: A web-based personalized feedback program. Journal of Substance Abuse Treatment, 34, 263271.

Doumas, D. M., \& Haustveit, T. (in press). Reducing heavy drinking in intercollegiate athletes: Evaluation of a Web web-based personalized feedback program. The Sport Psychologist.

Hingson, R. W., Heeren, T., Winter, M., \& Wechsler, H. (2005). Magnitude of alcohol-related mortality and morbidity among U.S. college students ages 18-24: Changes from 1998-2001. Annual Review of Public Health, 26, 259-279.

Hingson, R. W., Heeren, T., Zakocs, R. C., Kopstein, A., \& Wechsler, H. (2002). Magnitude of alcohol-related mortality and morbidity among U.S. college students ages 18-24. Journal of Studies on Alcohol, 63, 136-144.

Knight, J. R., Wechsler, H., Kuo, M., Seibring, M., Weitzman, E. R., \& Schuckit, M. (2002). Alcohol abuse and dependence among U.S. college students. Journal of Studies on Alcohol, 63, 263-270.

Kypri, K., Saunders, J. B., \& Gallagher, S. J. (2003). Acceptability of various brief intervention approaches for hazardous drinking among university students. Alcohol and Alcoholism, 38, 626-628.

Kypri, K., Saunders, J. B., Williams, S. M., McGee, R. O., Langley, J.D., Cashell-Smith, M. L., et al. (2004). Web-based screening and brief intervention for hazardous drinking: A doubleblind randomized controlled trial. Addiction, 99, 1410-1417. 
Larimer, M. E., \& Cronce, J. M. (2002). Identification, prevention, and treatment: A review of individual-focused strategies to reduce problematic alcohol consumption by college students. Journal of Studies on Alcohol, Supplement, 14, 148-163.

Larimer, M. E., \& Cronce, J. M. (2007). Identification, prevention, and treatment revisited: Individual-focused college drinking prevention strategies 1999-2006. Addictive Behaviors, 32, 2439-2468.

Larimer, M. E., Turner, A. P., Anderson, B. K., Fader, J. S., Kilmer, J. R., Palmer, R. S., et al. (2001). Evaluating a brief alcohol intervention with fraternities. Journal of Studies on Alcohol, 62, 370-380.

Marlatt, G. A., Baer, J. S., Kivlahan, D. R., Dimeff, L. A., Larimer, M. E., Quigley, L. A., et al. (1998). Screening and brief intervention for high-risk college student drinkers: Results from a 2-year follow-up assessment. Journal of Consulting and Clinical Psychology, 66, 604615.

Miller, E. T., Neal, D. J., \& Roberts, L. J., Baer, J. S., Cressler, S. O., Metrik, J., et al. (2002). Testretest reliability of alcohol measures: Is there a difference between internet based assessment and traditional methods? Psychology of Addictive Behaviors, 16, 56-63.

Miller, W. R., \& Rollnick, S. (2002). Motivational interviewing: Preparing people to change addictive behavior (2nd Ed). New York, NY: Guilford Press.

Moyer, A., Finney, J. W., Swearingen, C. E., \& Vergun, P. (2002). Brief interventions for alcohol problems: A meta-analytic review of controlled investigations in treatment-seeking and non-treatment seeking populations. Addiction, 97, 279-292.

National Institute on Alcohol Abuse and Alcoholism (2003). Task Force on Recommended Questions of the National Council on Alcohol Abuse and Alcoholism: Recommended Sets of Alcohol Consumption Questions, October 15-6, 2003.

Neal, D. J., \& Carey, K. B. (2004). Developing discrepancy within self-regulation theory: Use of personalized normative feedback and personal strivings with heavy-drinking college students. Addictive Behaviors, 29, 281-297.

Neighbors, C., Larimer, M. E., \& Lewis, M. A. (2004). Targeting misperceptions of descriptive drinking norms: Efficacy of a computerdelivered personalized normative feedback intervention. Journal of Consulting and Clinical Psychology, 72, 434-447.
Perkins, H. W. (2002). Social norms and the prevention of alcohol misuse in collegiate contexts. Journal of Studies on Alcohol, Supplement, 14, 164-172.

Saunders, J. B., Kypri, K., Walters, S. T., Laforge, R. G., \& Larimer, M. E. (2004). Approaches to brief intervention for hazardous drinking in young people. Alcoholism: Clinical \& Experimental Research, 28, 322-329.

Scanlon, T. (n.d.). The Judicial Educator on www.reslife.net: Bringing together education and discipline. Retrieved October 29, 2007, from http://www.reslife.net/html/in_the_news_d.html

Vik, P. W., Carrello, P., Tate, S. R., \& Field, C. (2000). Progression of consequences among heavy-drinking college students. Psychology of Addictive Behaviors, 14, 91-101.

Walters, S. T., Miller, E., \& Chiauzzi, E. (2005). Wired for wellness: e-Interventions for addressing college drinking. Journal of Substance Abuse Treatment, 29, 139-145.

Walters, S. T., \& Neighbors, C. (2005). Feedback interventions for college alcohol misuse: What, why, and for whom? Addictive Behaviors, 30, 1168-1182.

Walters, S. T., Vader, A. M., \& Harris, T. R. (2007). A controlled trial of web-based feedback for heavy drinking college students. Prevention Science, 8, 83-88.

Wechsler, H., Lee, J. E., Kuo, M., \& Lee, H. (2000). College binge drinking in the 1990s: A continuing problem. Results of the Harvard School of Public Health 1999 College Alcohol Study. Journal of American College Health, 48, 199-210.

Wechsler, H., Lee, J. E., Kuo, M., Seibring, M., Toben, N., \& Lee, H. (2002). Trends in college binge drinking during a period of increased prevention efforts. Journal of American College Health, 50, 203-217.

White, H. R., \& Labouvie, E. W. (1989). Towards the assessment of adolescent problem drinking. Journal of Studies on Alcohol, 50, 30-37.

White, H. R., Morgan, T. J., Pugh, L. A., Celinska, K., Labouvie, E. W., \& Pandina, R. J. (2006). Evaluating two brief substance-use interventions for mandated college students. Journal of Studies on Alcohol, 67, 309-317.

White, H. R., Mun, E. Y., Pugh, L. A., \& Morgan, T. J. (2007). Long-term effects of brief substanceuse interventions for mandated college students: Sleeper effects of an in-person personal feedback intervention. Alcoholism, Clinical and Experimental Research, 31, 1380-1391. 
Table 1

Means and Standard Deviations for Drinking Variables, Alcohol-Related Problems, and Estimates of Peer Drinking

$\begin{array}{ccccc}\text { Quantity of } & \text { Peak Alcohol } & \text { Drinking to } & \text { Alcohol-Related } & \text { Estimates of } \\ \text { Peer Drinking } \\ \text { Condition }\end{array}$

Feedback $^{\mathrm{a}}$

$\begin{array}{llllll}\text { Baseline } & 8.16(6.59) & 8.77(4.53) & 0.84(0.37) & 2.92(3.62) & 14.96(0.20) \\ \text { Follow Up } & 4.89(3.88) & 6.95(3.92) & 0.68(0.47) & 1.38(2.27) & 12.63(5.92)\end{array}$

Education $^{\mathrm{b}}$

Baseline

7.04 (5.30)

$6.21(2.77)$

$0.79(0.41)$

2.67 (2.97)

$11.92(6.26)$

Follow Up

$5.77(5.91)$

$5.88(3.07)$

$0.71(0.46)$

$1.54(3.27)$

$11.31(5.30)$

${ }^{\mathrm{a}} n=37 .{ }^{\mathrm{b}} n=24$. 
Table 2

Regression Analyses for Change in Estimates of Peer Drinking as a Mediator on the Effect of the Intervention on Changes in Drinking

\begin{tabular}{lccc}
\hline Variable & $B$ & $S E$ & $\beta$ \\
\hline Step 1 & & & \\
$\quad$ Intervention & 3.09 & 1.51 & $.31^{*}$ \\
$\quad$ Step 2 & & & .15 \\
$\quad$ Intervention & 1.46 & 1.41 & $.48^{* * *}$ \\
$\quad \Delta$ Peer Drinking Estimates & 0.33 & 0.08 & \\
\hline
\end{tabular}

Note. $R^{2}=.27, \mathrm{p}<.001$.

$* p<.05, * * * p<.001$. 
Figure Captions

Figure 1. Changes in Drinking Variables by Intervention
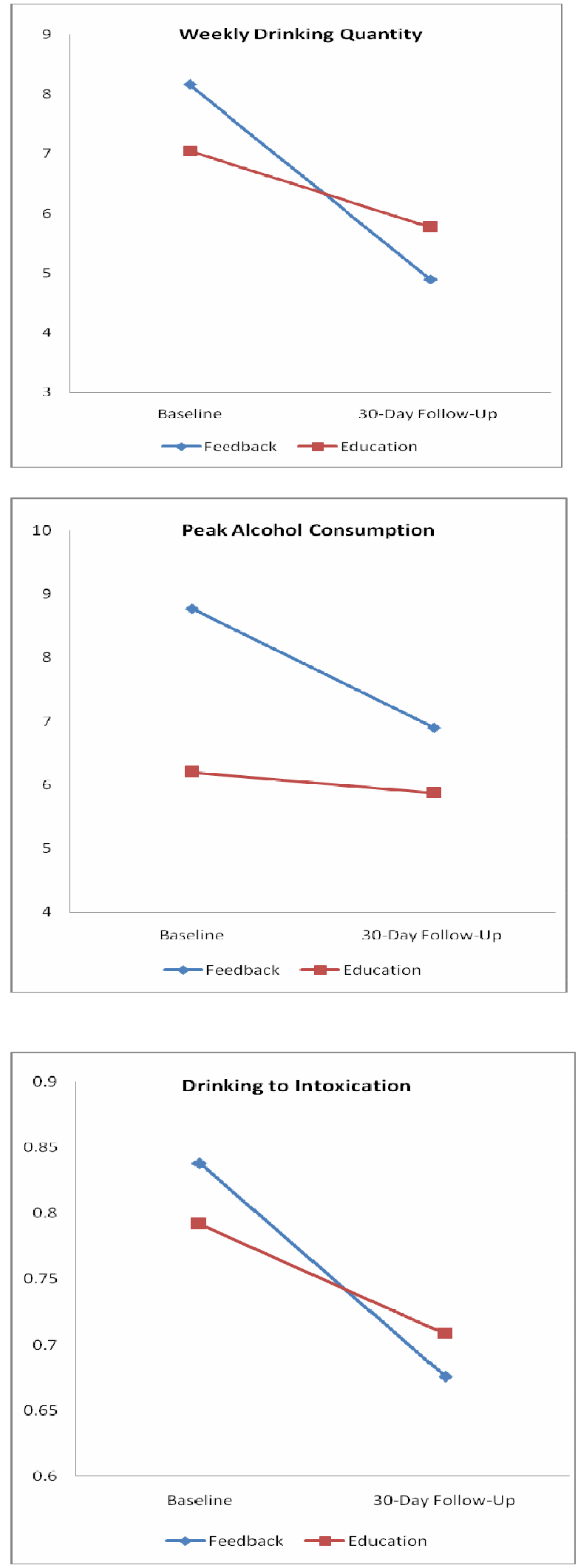